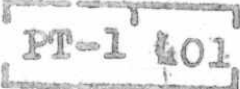

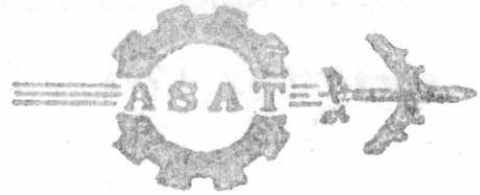

MILITARY THCHNICAL' C'ULLLIOL.

CAIRO - ELYH'T

C

Effect of Copper And Zinc Additives On The Corrosion Rate of Aluminium alloys In Aqueous Solutions

\author{
M. M. SELEET ${ }^{*}$, A. ELBAZ ELSAIID*,
}

H. FARAG ${ }^{\star \star}$

\title{
ABS'RACT
}

The corrosion behavior of five Al-alloys containing different amounts of copper $(0-4 \%)$ or zinc $(0-6 \%)$ was investigated in aqueous solutions of ammonium chloride, ammonium ritrate, sodium chloride, sodium hydroxide, and sodium silicate uaing weight loss measurements and eletrochemical methods, namely corrosion potential, polarization and cyclic polarization techniques. The results show that copper (or zinc) has an accelerating effect on the corrosion rate of the investigated alloys in all previous solutions except sodium hydroxide solution , where it has an inhibiting effect. The accelerating effect is explained by an anodic (in sodium chloride, sodium silicate, and amonium chloride solutions) and cathodic (in ammonium nitrate solution) depolarization mechanism. The intibiting effect is explained by an anodic polarization mechanism.

* Chem. Eng. Branch, Military Technical College, Cairo, Egypt. x. Armament Authority, Cairo, Egypt. 


\section{INTRODUCTI ON}

The corrosion rate measurements and pitting of different aluminium alloys were investigated by many authors [1-7]. Galuanic coupling of copper alloys with aluminium in $(0.01-1 \mathrm{~N})$ sodium chloride solution showed that the increase in the dissolution rates of aluminium in different concentrations of sodium chloride was cathodically controlled and proportional to the average galyanic current density [8]. Chaudhary and others [9] showed that tungstate ions stimulate the corrosion of aluminium ty acting as a cathodic depolarizer while morpholine polarizes local cathodic sites, acting as an inhibitor. A four-steps model was proposed for the localized corrosion of Al-alloys by Foley [10]. In $3.5 \%$ sodium chloride solution, the Al-alloy 2024 exhibited considerable corrosion attack, attributed to a cathodic control mechanism [11].

Although the corrosion of Al-alloys has been studied in a large uariety of aqueous solutions, the specific role of some additives , e.. copper and zinc, has not been fully clarified. The aim of the present work is to investigate the individual effect of copper and zinc additions on the corrosion behaviour of Al-alloys in certain aqueous solutions.

\section{EXPERIMENTAL}

\section{Material:}

Five. Al-alloys of different compositions, Table 1., were casted in metallurgy laboratories, M.T.C., Cairo, Egypt. Rectangular sheets of $40 \times 30 \times 3 \mathrm{~mm}$ and $10 \times 10 \times 3 \mathrm{~mm}$ were prepared as testing specimens for weight loss and polarization measurements, respectively. Samples were polished, degreased, washed and finally dried, according to sample preparation standards [12].

\section{Solutions:}

Aqueous solutions of ammonium chloride; ammonium nitrate, sodium chloride, sodium hydroxide, and sodium silicate, of one molar concentration each, were prepared from reagent grade chemicals using distilled water. Lower concentrations of sodium chloride and sodium hydroxide solutions were prepared, by successive dilution, whenever needed.

3. Techniques and Apparatus:

Weight loss measurements were conducted using sartorius analytical balance (Germany) of maximal sensitivity $0.1 \mathrm{mg}$ and 
accuracy t $0.2 \mathrm{mg}$. The electrochemical tests ( corrosion potential, polarization, and cyclic polarization measurements) were conducted by an electronic potentiostat, model Tacussel PRT 10-05L, equipped with a pilot scanner, electronic millivoltmeter and an $X-Y$ recorder, magufactured by Tacussel Electronique. The working electrode, one $\mathrm{cm}^{2}$ area, was fixed in a cylinder of cold setring. resin, while electric contact was realized by using a copper wire immersed in mercury. The samples were scanned from cathodic to anodic region in the potential range of $\$ 250 \mathrm{mV}$ w.r.t. the predetermined corrosion potential, at a scan rate of $20 \mathrm{~mW} / \mathrm{min}$, in stirred aqueous solutions. A scan rate of $60 \mathrm{mV} / \mathrm{min}$ was used for cyclic polarization experiments.

\section{RESULTS}

1. Weight Loss Results:

The effect, of copper additions on the weight loss of Al-alloys in the investigated aqueous solutions, is shown in Table 2. The corrosion rate increased with the copper content increase in all solutions except sodium hydroxide where corrosion rate decreased. Similarly, the corrosion rate of Al-alloys decreased in NaOH but increased in other solutions with the increase of Zn-content, Table 3 .

\section{Corrosion Potential Results:}

The steady state corrosion potentials of Al-alloys in the investigated aqueous solutions are shown in Table 4. Al alloys were found the lesst noble in $\mathrm{NaOH}$ and the most noble in $\mathrm{NH}_{4} \mathrm{NO}_{3}$ solution. Also, alloy 120 was the most noble in all solutions exeept $\mathrm{NaOH}$ and $\mathrm{NH}_{4} \mathrm{NO}_{3}$. The change of corrosion potential with time for Al-alloys in $\mathrm{Na}_{3} \mathrm{AO}_{3}$ and $\mathrm{NH}_{\mathrm{C}} \mathrm{Cl}$ solutions is shown in Fig.1 and Fig.2. Similar curves were obiained in other solutions.

3. Determination of Electrochemical Parameters From Tafel Plots:

The corrosion potential, Ecor, and corrosion current, icor, of Al-alloys were determinegographically from polarization" curves of these alloys in the innestigated aqueous solutions. Due to the severe corrosion of Al-al.oys in $1 \mathrm{M} \mathrm{NaOH}$ solution noticed during the weight loss tests, a more dilute solution, namely $1 \times 10^{-4} \mathrm{M}$, was used in polarization experiments. for the same reason, sodium chloride solution of $0.1 \mathrm{M}$ was used. The polarization curves in $1 \times 10^{-4} \mathrm{M} \mathrm{NaOH}$ solution ire shown in Fig.3 and Fig.4. Similar curves were obtained in ther solutions. The numerical values are summarized in Table j. It is clear that in $1 \times 10^{-4} \mathrm{M} \mathrm{NaOH}$, Al-alloy 120 has the largest corrosion current value, while in 
all other solutions, it has the lowest value of corrosion surent.

4. Eyclic Folarization Results:

The cyclic polarization results of Al-alloys in the investigated solutions are classified into two groups. The curves of the

first group are characterizeo by the following features:

э. The reversed anodic current is higher than the corrosion current (measured at the corrosion potential) by, at least, one
deade.

b. The corrosion potential, extiacted from the reverse scan, occurs at less noble potential than the original one.

The curves of the second group miss one (or all) of the previous features. The results show that the first group includes Alalloys 121 and 122 in aqueous solutions of NHACl and NaCl. All other combinations are included in the second group. Examples of cyclic polarization results are shown in Fig.5 and Fig. 6 for Alalloy 120 in $1 \mathrm{M} \mathrm{NH}_{4} \mathrm{NO}_{3}$ (second group) and Al-alloy 121 in $0.1 \mathrm{M}$ NaCl solution (first group), respectively.

\section{SCUSSION}

The results of weight loss show that the corrosion rates of all Al-alloys in sodium chloride, sodium silicate and ammonium chloride solutions were small. (not renarkable). The most probable reaction in these solutions is:

$$
\mathrm{Al}+3 \mathrm{H}_{2} \mathrm{O}-\ldots+\ldots+\mathrm{Al}(\mathrm{OH})_{3}+3 \mathrm{H}^{+}+3 \mathrm{e}
$$

In ammonium nitrate solution, where corrosion rates were moderate, the corrosion action may be attribnted to the formation of nitric acid with low concentrations which has a corrosive effect arid the more favored reaction is;

$$
\text { AI }
$$

In sodium hydroxide solution, the remarhably high carrosion rates can be explained by the amphoteric propert? of aluminium and formation of soluble aluminatss.

In solutions where corrosion pate wes low or moderate, the general effect of Cll or Zn addition whs found to increase the Alalloy corrosion with increase of cu or Zn percentage, Tables 2. corrosion increases, in NH cl solution (corrosion is i i tele), the corrosion increases with the increase of zos g and this effect is 
prominent in $\mathrm{NH}_{4} \mathrm{NO}_{3}$ solution, where corrosion rate is moderate, Table 3. However, in $\mathrm{NaOH}$ solution, where corrosion rate is very high, it is clear that $C u$ or $Z_{n}$ has an inhibiting effect on the corrosion behavior of Al-alloys.

The corrosion potential results, Table $4:$, show that all the tested alloys have their noble potentials in $\mathrm{NH}_{4} \mathrm{NO}_{3}$ solution, and their basic potentials in $\mathrm{NaOH}$ solution, while the potentials in the other three solutions are inbetween. Relating the weight loss results to the corrosion potential values, it is clear that corrosion rate is low in the potential range -500 to $-850 \mathrm{mu}$, moderate at -100 to $-350 \mathrm{mV}$, and very severe around the potential of $-1300 \mathrm{~m}$. Although the results of corrosian potential extracted from polarization curves are not exactly the same as those measured before, Table 4. . yet the results have the same trend of relative nobility of different alloys in various solutions. The noticeable differences in case of $\mathrm{NaOH}$ solutions may be attributed to the difference in concentration. According to corrosion parameters determined from polarization curves, Table 5., it is clear that in the solutions of NaCl, $\mathrm{Na}_{2} \mathrm{SiO}_{3}$ and $\mathrm{NH}_{4} \mathrm{Cl}$ the addition of $\mathrm{Cu}$ (or $\mathrm{Zn}$ ) increases the corrosion current and shifts $E_{\text {cor }}$ to less noble potential. This can be explained on the basis of anodic depolarization, shown by Evans diagram, Fig.7.

In ammonium nitrate solution, where the corrosion reaction is different', the increase of copper (or zinc) content results in higher values of $i$ and shifts $E$ cor to more positive values, i.e. copper (or zinç acts as cathodich depolarizer, Fig.8.

in sodium hydroxide solution, the remarkably high corrosion rate of Al-alloys is generally attributed to the formation of soluble Na-aluminete. However, the increase of $\mathrm{Cu}$ (or $\mathrm{Zn}$ ) content decreases the corrosion rate and shifts corrosion potential ro more noble values, suggesting that $C u$ (or $Z_{n}$ ) may act as anodic polarizer, Fig.7.

The evclic polarization curves at constant scan rate were used co predict pit formation $[13,14]$. The pit formation may be predicted when the cyclic polarization curve has the following features:

a. The reversed anodic current is higher than the corrosion current (measured at the corrosion potential) by, at least, one decade.

b. The corrosion potential, extracted from the reverse scan, occurs at less noble potential than the original one.

The present results show that pit formation can be predicted only in aqueous solutions of $\mathrm{NaCl}$, and $\mathrm{NH}_{4} \mathrm{Cl}$, and only for alloys 121 and 122. These results are in accordance with the visual inspection of samples after the immersion for 24 hours. So, in $\mathrm{NH}_{4} \mathrm{NO}_{3}$ and $\mathrm{NaOH}$ solutions, where corrosion is moderate or extengive and no chloride ions are present, the anodic 
Ins In adition occurs on the whole surface and ho pits are formed. farmation, the present results the known effect of chioride ions on pit increases the probability of pit reweal the role of copper which and $\mathrm{NH}_{4} \mathrm{Cl}$ solutions. In absence pit formation on Al-alloys in $\mathrm{NaCl}$ Al-alloy 120 is very low in these of coprosian rate of addition of copper (Al-bllous 121 solutions. However, the Eorrosion rate and accordingly the 121 and 122 increases the This is confirmed by the fact the probability of pit formation. if traces of copper are present pitting is greatiy increased copper may slowly deposit by mentin the aqueous medium. The cathodic surface which increases cathodic reaction providing a

\section{CONCLUSI ONS}

1- The corrosion rate, of Al-alloys with (or without) copper or sodium silicate and sodium solutions of ammonium chloride, nitrate, and very high in sodium hudroxide moderate in ammonium - In all solutions (except sodium hydroxide) copper (or zinc)
acts as an accelerator of Al-alloys corrosion zor a acts as an accelerator of Al-alloys corrosion.

3- In sodium hydroxide solution, copper (or zinc) acts as an
inhibitor of Al-alloys corrosion.

4- The accelerating effect of copperorghrom anodic (or cathodic) depolarizapfer or zinc is explained by efrect is explained by anodic polarization mentanismo bing

Pitting corrosion can be predicted in case of Al-alloys solutions. 


\section{RFFFFFNCES}

1. Erali,A. and Holtan,H. ; Corrosion Science, Yol. 13, p.237

(1973)
Brali,A. Holtan, H. and Frestrud, K.L.; Corrosion, Vol. 30,
0.427 (1974) F.427 (1974) Hensetenberg, D.H. and Kenkel,J.U.; Corrosion,

3. Mansfeld,F. i Herigstent
Vol. Bt, p.10 (1974)

4. Alcibiades, B. and Darty, R.; Corrosion, Vol. 30, P.5 (1974)

5. Mansfeld,F, and Kenkel,J.U.; Corrosion Science, Vol. 15 , $0.183(1975)$

E. Eroli A. and Holtan, H.; Corrosion seience, Vol.17, p.59(1977)

F Yadau,P.N.S.; Singh,D.D.N.; Chaudhary,R.S. and Agrawal, C.U.; Indian lournal of Technology, Vol. 19, P. 461 (1981)

Q. Ismal 1,A.A.; El-Sobki,K.M.; Khedr,A.A. and Sanad,S.H.; Curosion Freuention Control, vol.30, p.13 (1983)

9. Clandhary,R.S.; Yadav,P.N.S. and Agrawal, C.V.; Journal of Ap 21 ied Electrochemi

10. F.ley,R.T.; Corrosion, Vol.42, p.5 (1986)

11. Suat, W. [.; Corrosion, Vol. 42, p.9 (1986) 2. rilor, W.H.; Handbook on Corrosion Testing
John Wiley \& sons, New York, p.124 (1971)

1. Hilide.E.E.; Corrosion, Uol. 28, p. 283 (1972)

3. Walker,M.S. and Rowe,L.C.; Electrocherical Techniques far Corrojon, Eaboian,f. ed., NACE: Houston, f.79 (1978) 
r

Tatile 1 The Chemical Composition of the Al- alloys tested" (\% wt)

\begin{tabular}{llll}
\hline Alloy No. & $\mathrm{Mg}$ & $\mathrm{Cu}$ & $\mathrm{Zn}$ \\
\hline 120 & 2.36 & $\cdots$ & $\cdots$ \\
121 & 2.47 & 1.93 & $\cdots$ \\
122 & 2.55 & 4.12 & $\cdots$ \\
123 & 2.60 & $\cdots$ & 2.55 \\
124 & 2.40 & $\cdots$ & 6.00 \\
\hline
\end{tabular}

* The remainder is $\mathrm{Al}$

Tatile 2 Effect of Copper Additions on Weight Loss Results for Al- alloys in Several Aqueous Solutions (1M concentration) at $25^{\circ} \mathrm{C}$

\begin{tabular}{lllllll} 
Alloy & $\mathrm{Cu} \%$ & Wr. loss in aqueous solutions $\mu \mathrm{g} / \mathrm{m}^{2} \mathrm{~S}$ \\
\cline { 3 - 7 } & & $\mathrm{NaCl}$ & $\mathrm{Na}_{2} \mathrm{SiO}_{3}$ & $\mathrm{NH}_{4} \mathrm{Cl}$ & $\mathrm{NH}_{4} \mathrm{NO}_{3}$ & $\mathrm{NaOH}$ \\
\hline 120 & 0.00 & 0.34 & 0.64 & 1.36 & 0.00 & 4105.51 \\
121 & 1.93 & 5.28 & 3.70 & 6.30 & 23.67 & 2121.96 \\
122 & 4.12 & 7.47 & 9.98 & 12.55 & 20.77 & 1874.10
\end{tabular}


Tuble 3 Effect of Zinc Addieions on Weight Loss Results for Al-allous in Several Aqueous Solutions ( 1 M concentration) at $25^{\circ} \mathrm{C}$

\begin{tabular}{lllllll}
\hline Alloy & Zn\% & \multicolumn{4}{c}{ Wt. loss in squeous solutions, $\mu \mathrm{g} / \mathrm{m}^{2} \mathrm{~S}$} \\
\cline { 3 - 6 } & & $\mathrm{NaCl}$ & $\mathrm{Na}_{2} \mathrm{SiO}_{3}$ & $\mathrm{NH}_{4} \mathrm{Cl}$ & $\mathrm{NH}_{4} \mathrm{NO}_{3}$ & $\mathrm{NaOH}$ \\
\hline 120 & 0.00 & 0.00 & 0.64 & 1.36 & 0.00 & 4105.51 \\
123 & 2.55 & 0.34 & 1.13 & 1.87 & 6.22 & 1524.52 \\
124 & 6.00 & 0.44 & 1.77 & 2.75 & 12.30 & 1435.67
\end{tabular}

Table 4 Measured Corrosion Potential (open circuit potential) of Al-alloys in Aqueous Solutions ( $1 M$ concentration) at $25^{\circ} \mathrm{C}$ by Compensation Method

\begin{tabular}{llllll}
\hline & \multicolumn{5}{c}{ Measured Corrosion Potential, nV } \\
& $\mathrm{NaCl}$ & $\mathrm{Na}_{2} \mathrm{SiO}_{3}$ & $\mathrm{NH}_{4} \mathrm{Cl}$ & $\mathrm{NH}_{4} \mathrm{NO}_{3}$ & $\mathrm{NaOH}^{\circ}$ \\
\cline { 2 - 5 } 120 & -558 & -518 & -543 & -333 & -1348 \\
121 & -608 & -858 & -588 & -173 & -1228 \\
122 & -623 & -683 & -603 & -133 & -1198 \\
123 & -618 & -833 & -708 & -298 & -1288 \\
124 & -678 & -723 & -778 & -183 & -1228 \\
\hline
\end{tabular}




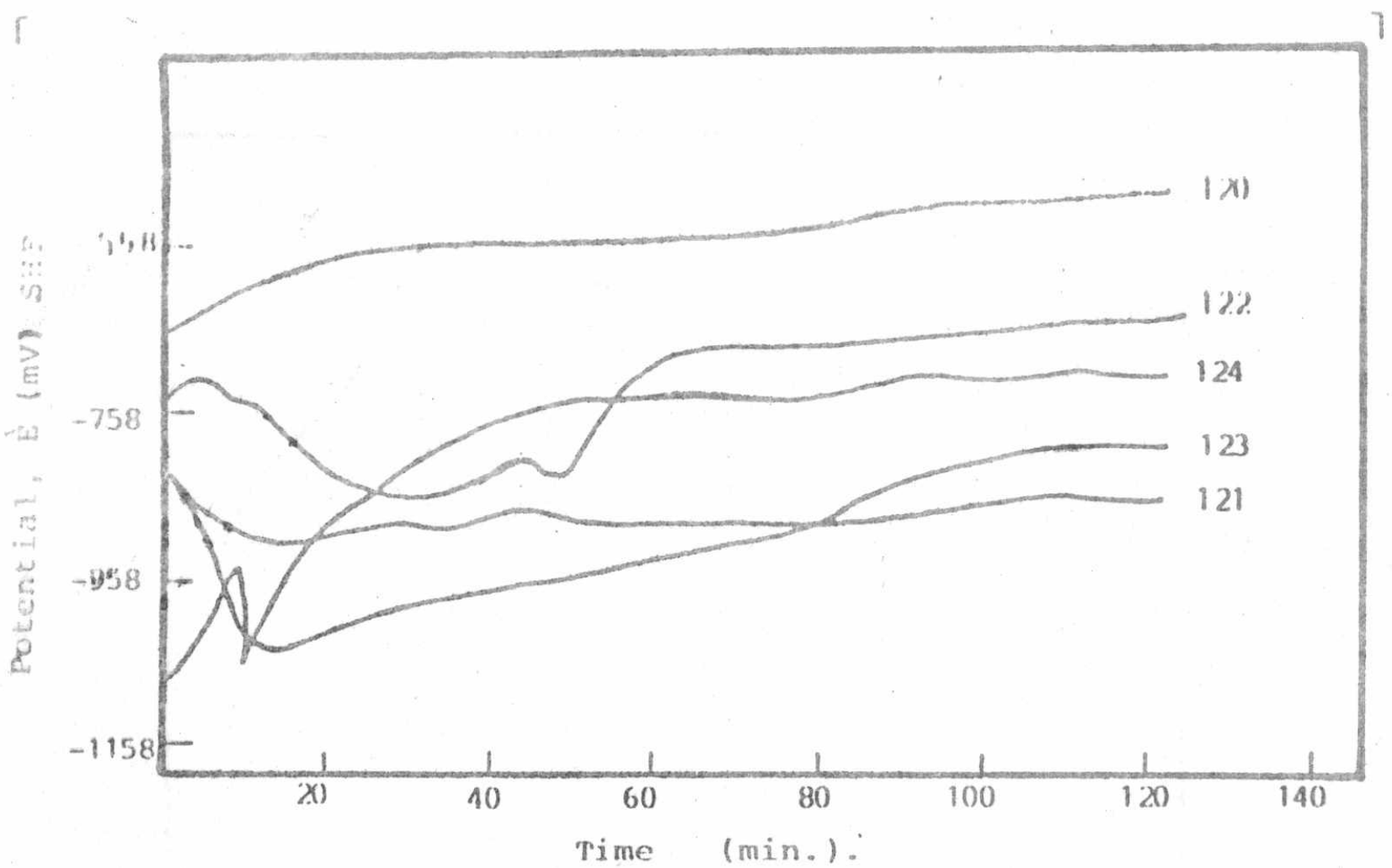

Fig. 1 corrosion potential us time curves for Al-alloys in iM sodium silicate solution at $25^{\circ} \mathrm{C}$.

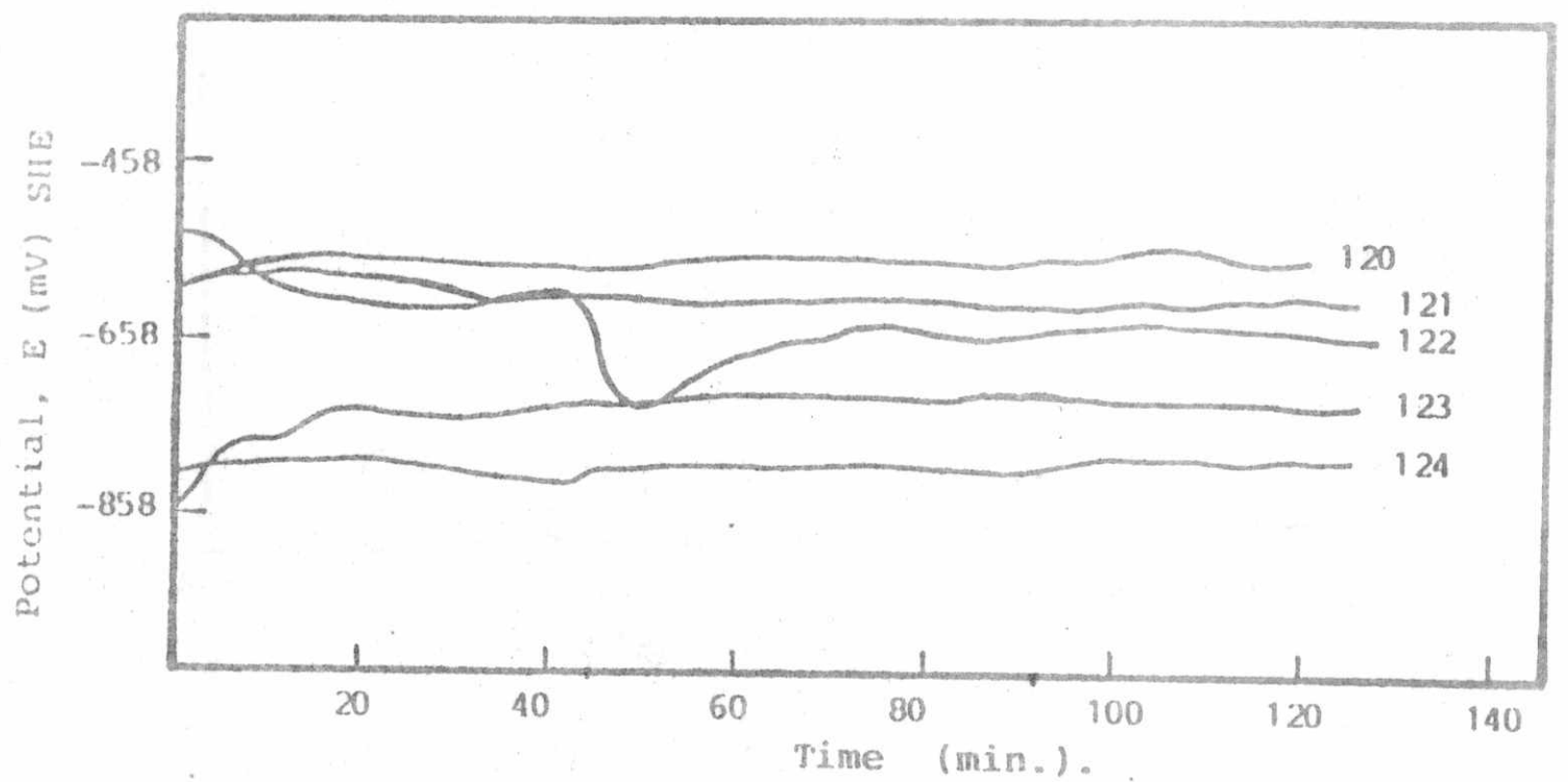

LFig. 2 Corrosion potential mst time curves for Al-alloys in $1 M$ ammenium chlbitide solution at $25^{\circ} \mathrm{C}$. 
「

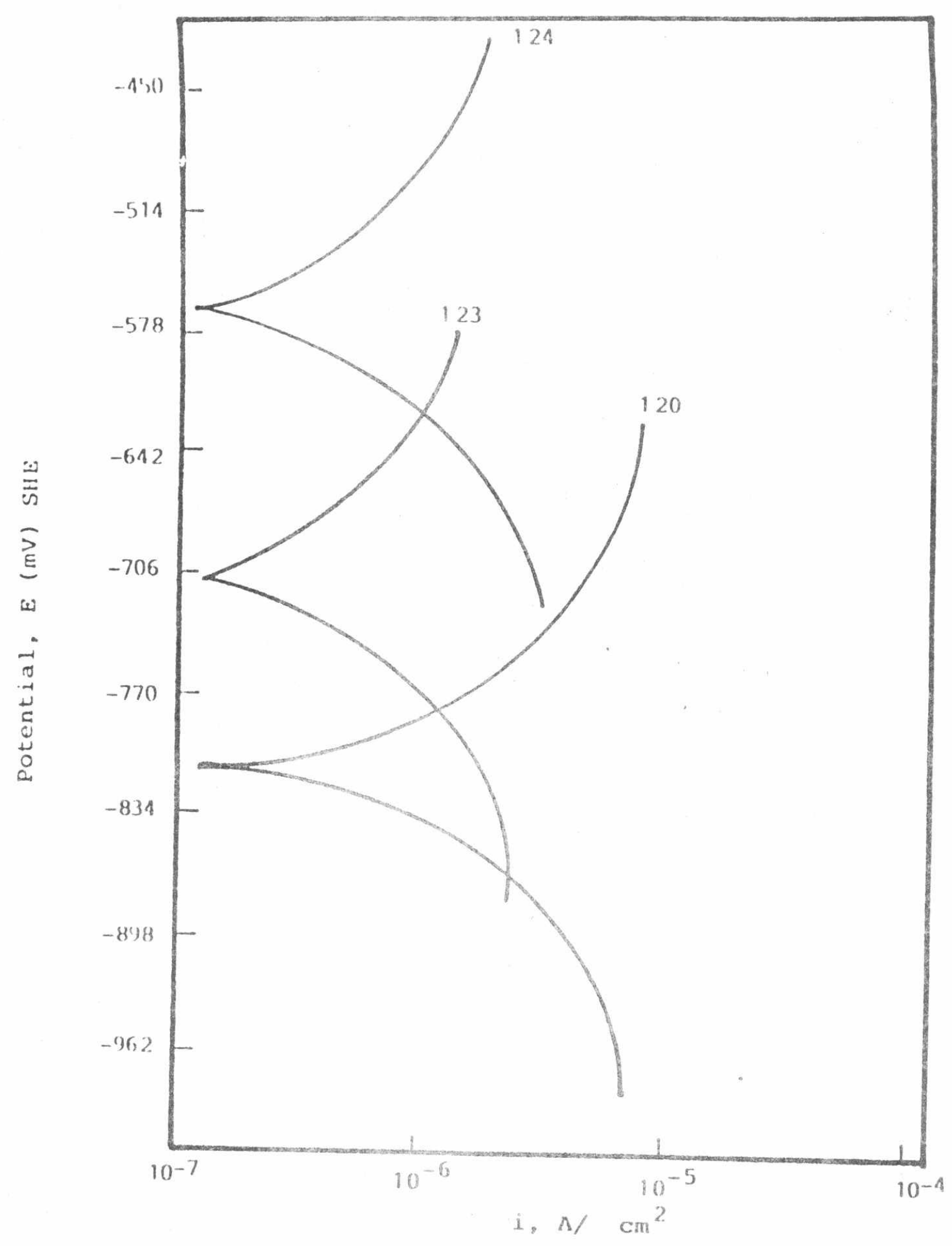

Fig. S Polarization curves for the tested Al-alloys (120, 123 and 124 ) in $1 \times 10^{-4} \mathrm{M}$ sodium fudpoxide solution at $25^{\circ} \mathrm{C}$. 


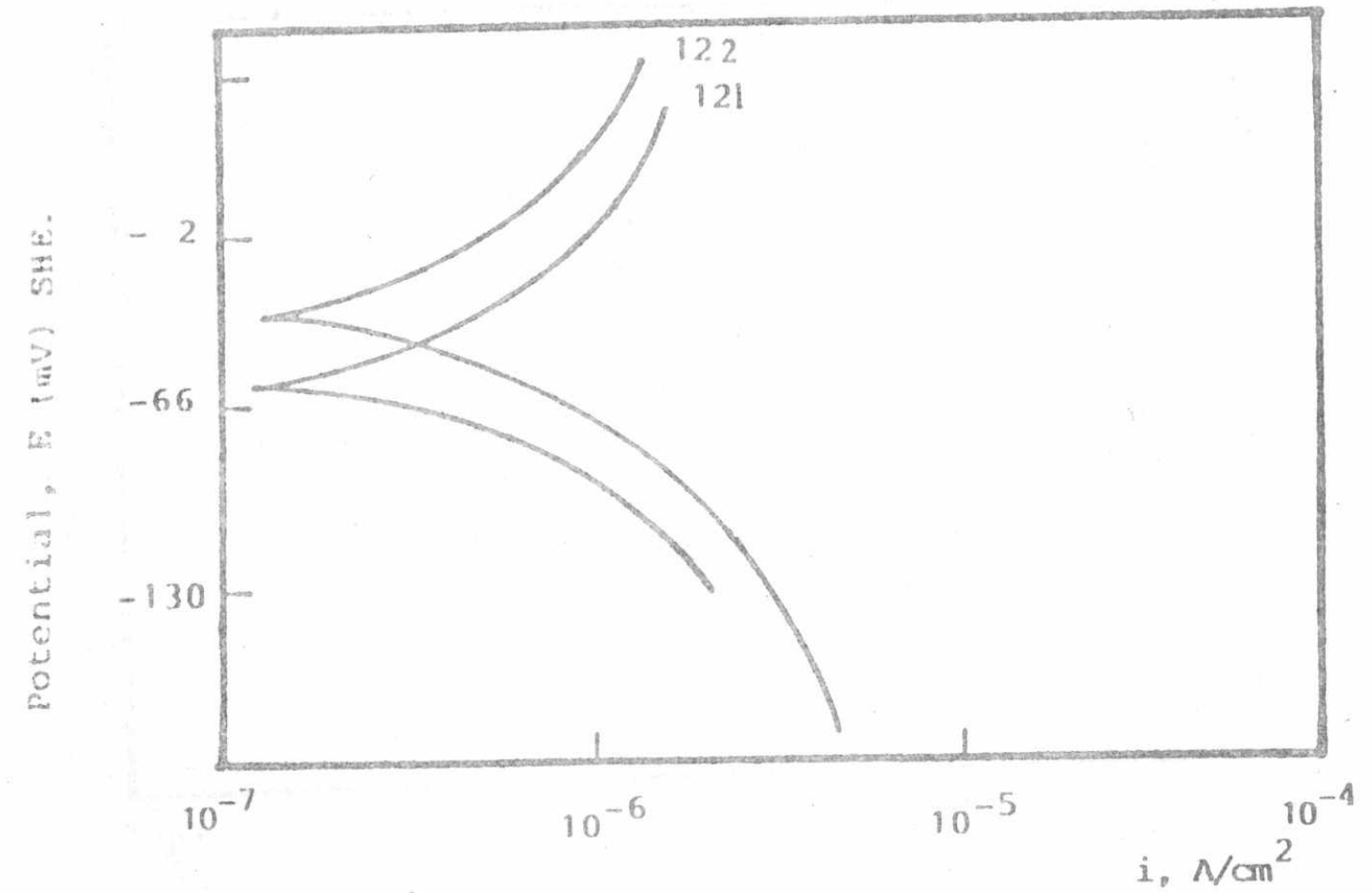
Fig. 4 Polarization cyrves for the tested Al-alloys $(121$ and
122 , in $1 \times 10^{\circ}$ M sodium hydroxide solution at $25^{\circ} \mathrm{C}$.

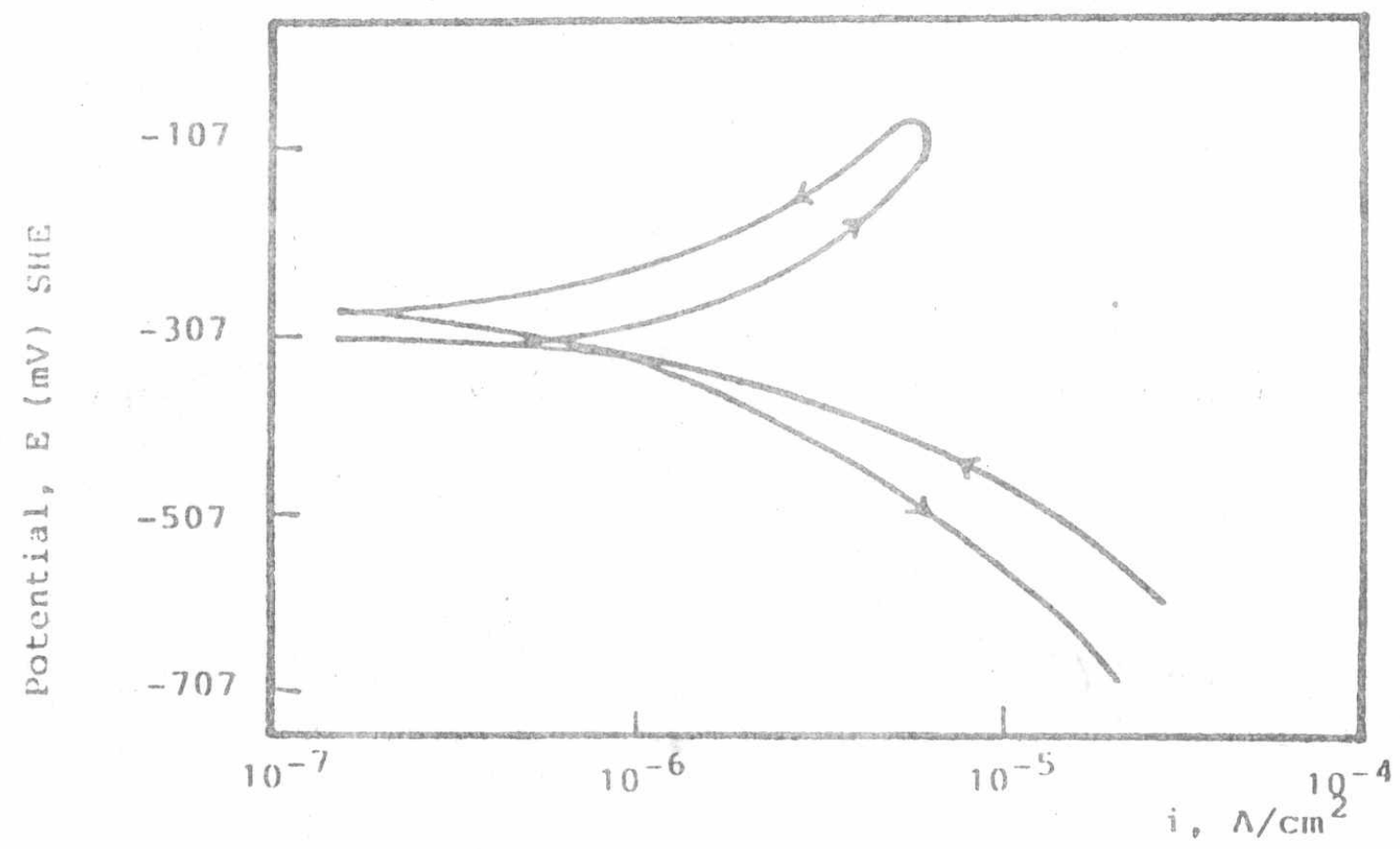

Fig. 5 Cyclic polarization curve for the tested Al-alloy 120 in 1 111 ammoniurn nitrate solution at $25^{\circ} \mathrm{C}$. 
PT-1 414

FOURTH ASAT CONFERENCE

$14-16$ May 1991, CAIKO

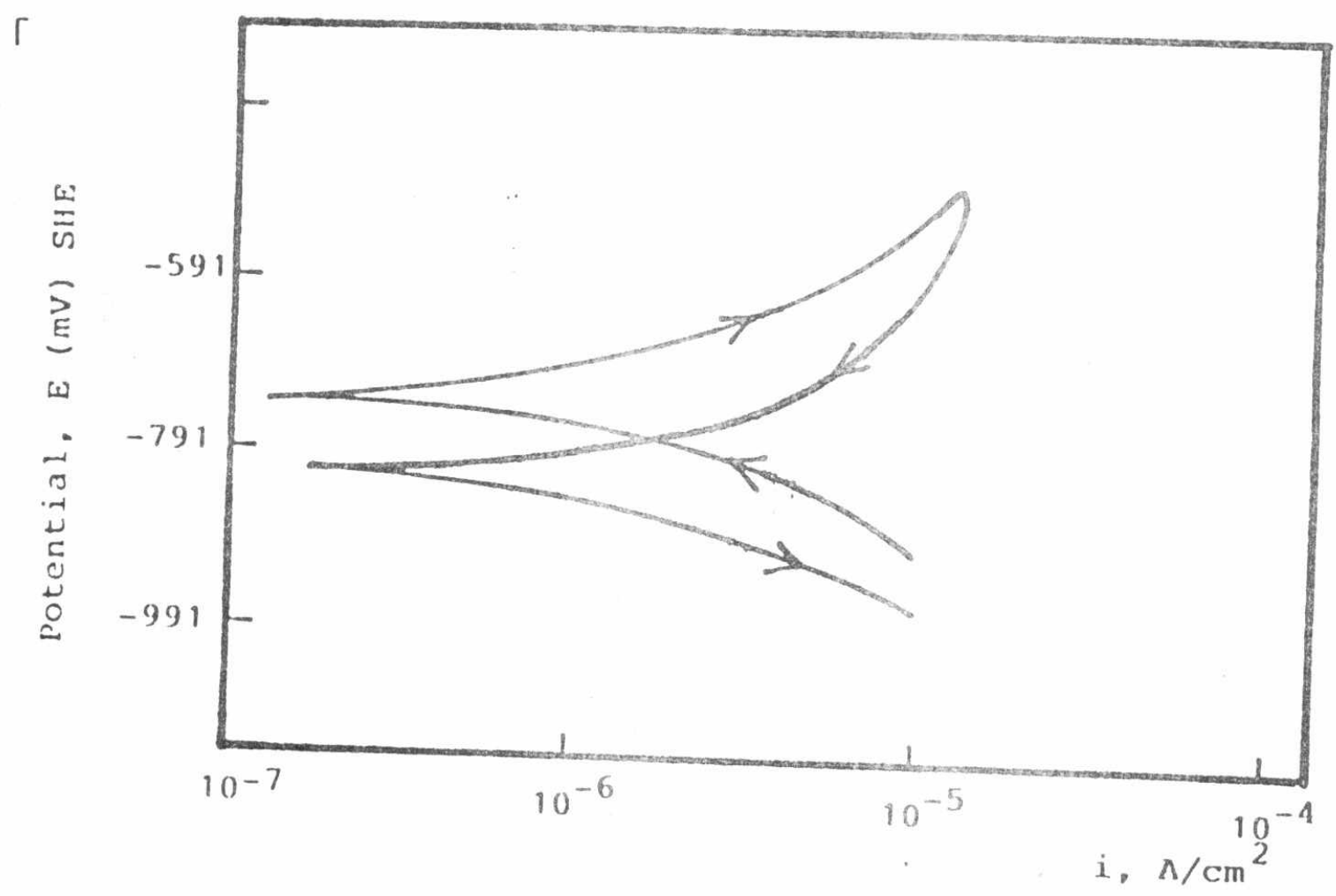

rig. 6 Cyclic polarization curve for the tested Al-alloy 121 in $1 \times 10^{-4} M$ sadium chloride solution at $25^{\circ} \mathrm{C}$.

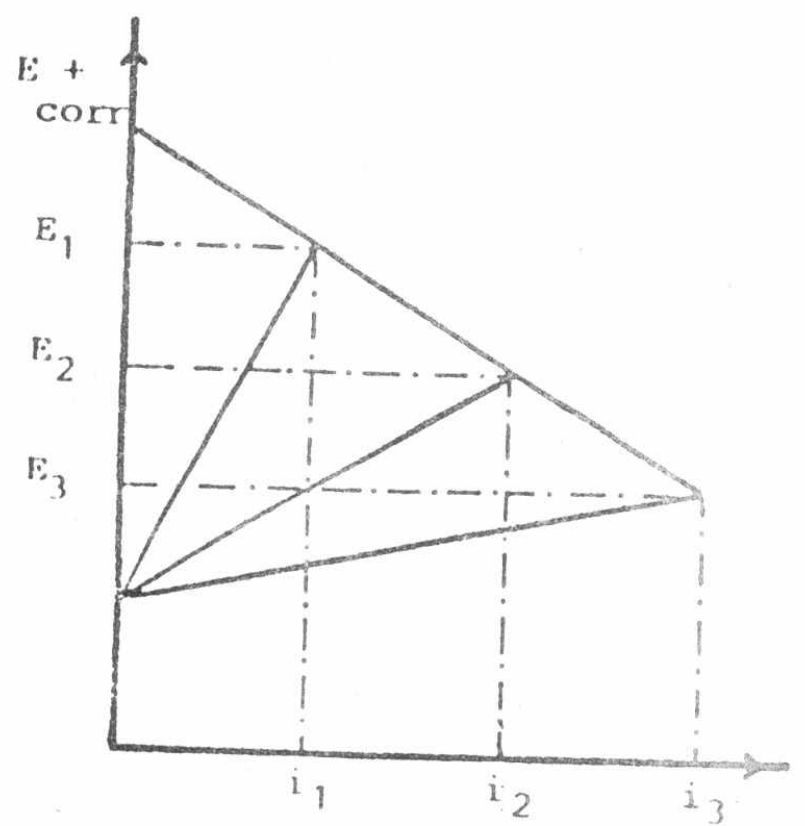

L Fig. 7 Anodic depolarizer.

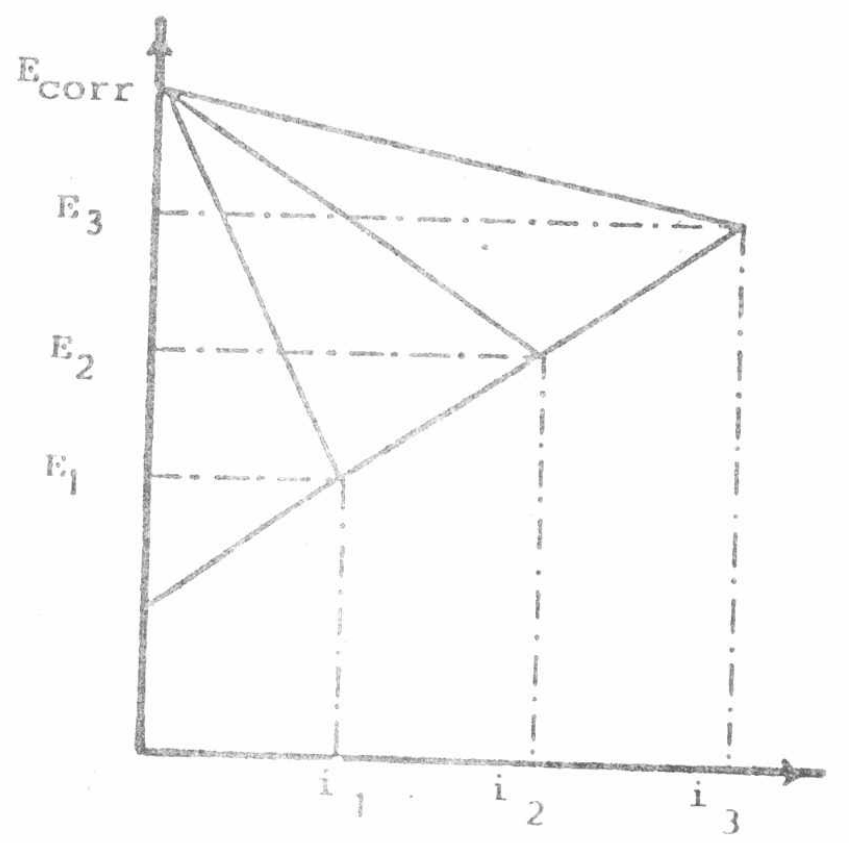

Fig. Gathodic depolarizer. 